\title{
Toward high-power nonlinear fiber amplifier
}

\author{
Hanwei Zhang, Pu Zhou, Hu Xiao, Jinyong Leng, Rumao Tao, Xiaolin Wang, Jiangming Xu, Xiaojun Xu, \\ and Zejin Liu \\ College of Advanced Disciplinary Studies, National University of Defense Technology, Changsha 410073, China \\ (Received 26 May 2018; revised 17 July 2018; accepted 19 July 2018)
}

\begin{abstract}
Stimulated Raman scattering (SRS) effect is considered to be one of the main obstacles for power scaling in general-type fiber lasers. Different from previous techniques that aim at suppressing SRS, nonlinear fiber amplifier (NFA), which manipulates and employs the SRS for power scaling in rare-earth-doped fiber, is under intensive research in recent years. In this paper, the authors will present an all-round study on this new kind of high-power fiber amplifier. A theoretical model is proposed based on the rate equation and amplified spontaneous emission (ASE), with random noise taken into account. By numerical solving of the theoretical model, the power scaling potential, heat analysis and advantages in suppressing the undesired backscattering light are quantificationally analyzed for the first time. Then two different types of high-power NFAs are demonstrated individually. Firstly, a laser diode pumped NFA has reached kilowatt output power, and the results agree well with theoretical predictions. Secondly, a tandem-pumped NFA is proposed for the first time and validated experimentally, in which $1.5 \mathrm{~kW}$ output power has been achieved. The authors also briefly discuss several new issues relating to the complex nonlinear dynamics that occur in high-power NFAs, which might be interesting topics for future endeavors.
\end{abstract}

Keywords: high-power fiber laser; nonlinear fiber amplifier; stimulated Raman scattering

\section{Introduction}

The output power of single chain fiber laser has been growing in recent years due to the fast development of pump laser diode (LD), active fiber, advanced heat management method, and so on. There has been a long time when stimulated Raman scattering (SRS) effect is considered to be one of the main obstacles for power scaling in general-type fiber lasers $^{[1-3]}$. The generation of SRS in fiber laser system might cause serious effects due to the backscattered Stokes light ${ }^{[4]}$. Therefore, SRS in high-power fiber laser system has been under intensive investigation and lots of technical solutions to suppress SRS have been proposed and validated, such as employing large-mode-area fiber, and decreasing the length of active fiber by using highly doped fiber ${ }^{[4-10]}$. Nevertheless, these are not intrinsic solutions and sometimes they would bring in side effects. For example, increasing the mode area would degrade the beam quality apart from mode control techniques. Using highly doped gain fiber may increase the thermal load per length and enhance the photondarkening effect. However, from the other point of view, SRS can be used to help lasing, which is often called Raman fiber

Correspondence to: P. Zhou and H. Zhang, College of Advanced Disciplinary Studies, National University of Defense Technology, Changsha 410073, China. Email: zhoupu203@163.com (P. Zhou), zhanghanwei100@163.com (H. Zhang) laser. Raman fiber laser has unique properties such as the broad gain spectrum and the wavelength versatility, which have been demonstrated in a large variety of wavelength bands ${ }^{[11-21]}$.

Up to now, most of the reported Raman fiber laser is achieved by core-pumping single-mode (SM) fiber, where the output power is determined directly by the pump laser. The maximal output power of the conventional core-pumped Raman fiber laser is about several-hundred-watt level ${ }^{[13-16]}$. In addition, the brightness can not be increased in the core-pumping configuration. Cladding pumped Raman fiber laser by using double-clad (DC) fiber has the potential for power scaling because of the significant increase in pump power ${ }^{[22-26]}$. In order to increase the conversion efficiency, specialized fiber is often required in cladding pumped fiber lasers, by which hundred-watt level output power has been achieved $^{[24]}$. It is to be noted that recently LD pumped Raman fiber laser based on multimode (MM) fiber has also drawn intensive attention ${ }^{[27-30]}$ because of its potential in brightness enhancement due to the self-beam cleanup effect in MM fiber ${ }^{[31,32]}$. Up to 140 watts level output power has been reported ${ }^{[30]}$. Generally, by now, pure Raman fiber lasers based on various kinds of configurations, including core-pumping SM fiber, cladding pumping DC fiber, and LD pumped MM fiber, have been successfully demonstrated. 
Nevertheless, the maximal output power is hundreds of watts, which is much lower than that of fiber lasers based on active fiber.

Recently, several independent groups have proposed a novel system setup ${ }^{[33-40]}$ named Yb-Raman fiber amplifier or nonlinear fiber amplifier (NFA, we call it nonlinear fiber amplifier in this paper), where laser gain provided by both SRS and active fiber is employed. In this new setup, the signal laser is firstly amplified via doped ions in the fiber and then the laser power is transferred into Stokes wave via SRS effect. Cladding pumping technique is employed in the system to ensure sufficient pumping power. Raman gain is employed designedly to induct forward scattered Stokes light and reduce the unwanted backscattered Stokes light. In addition, the system setup is compatible with standard fiber laser configuration that is usually based on master oscillator power amplifier (MOPA). Thus COTS active fiber and fiber components can be used without special design. Based on the aforementioned properties, NFA has achieved significant results in recent 5 years and has become a new route for high-power fiber lasers. Near $4 \mathrm{~kW}$ level output power based on $\mathrm{Yb}$ gain and Raman gain has been realized ${ }^{[37]}$, which is comparable with standard fiber laser/amplifier. And this concept has been extended to obtain high-power lasing at $2 \mu \mathrm{m}$ band based on both Tm gain and Raman gain ${ }^{[40]}$.

In the present paper, we provide a general and detailed study on high-power NFA. In Section 2, we present the physical modeling of the NFA. Based on the physical model, numerical programs are developed. The power scaling potential, effect of backscattered Stokes light suppression, and heat analysis of the NFA will be studied for the first time in Section 3. In Section 4, experimental results of NFA, including LD pumped NFA and tandem-pumped NFA will be demonstrated, where tandem-pumped NFA is presented for the first time. In Section 5, further investigation on several new issues, including the four wave mixing (FWM), the mode instability (MI) and photon darkening (PD) in the system will be presented. The conclusion and discussion on future endeavors will be drawn in Section 6.

\section{Modeling of nonlinear fiber amplifier}

The general system setup of an NFA is plotted in Figure 1. Without loss of conventionality, we focus on NFA based on $\mathrm{Yb}$-doped fiber in this paper. The NFA is similar to conventional Yb-doped fiber amplifier (YDFA) in system structure. The main difference is in the seed. It is a twoor multi-wavelength seed. The shortest wavelength usually locates at the gain peak of the Yb-doped fiber (YDF) and the other wavelengths correspond to each order of Raman Stokes waves. For example, if Seed 1 is $1070 \mathrm{~nm}$ laser, the wavelength of Seed 2 can be $1120 \mathrm{~nm}$ in silica fiber. It is to be noted that Seed 2 can also be provided by the spontaneous noise generated inside Seed $1^{[37]}$. Since the gain obtained from $\mathrm{Yb}$-ion and Raman scattering is based on different mechanisms, the phase-coupling between $\mathrm{Yb}$ gain and Raman gain can be neglected. In this case, the coupling between $\mathrm{Yb}$ gain and Raman gain can be achieved by intensity items. Such amplifiers can be numerically studied by a set of rate equations including both $\mathrm{Yb}$ and Raman amplifications $^{[34]}$.

$$
\begin{aligned}
& \frac{N_{2}(z)}{N(z)}=\left\{\sum_{s i} \frac{\left[P_{s i}^{+}(z)+P_{s i}^{-}(z)\right] \sigma_{a}\left(\lambda_{s i}\right) \Gamma_{s i}}{h v_{s i} A}\right. \\
& \left.+\sum_{k} \frac{\left[P^{+}\left(z, \lambda_{k}\right)+P^{-}\left(z, \lambda_{k}\right)\right] \sigma_{a}\left(\lambda_{k}\right) \Gamma_{k}}{h v_{k} A}\right\} \\
& \cdot\left\{\sum_{i} \frac{\left[P_{s i}^{+}(z)+P_{s i}^{-}(z)\right]\left[\sigma_{a}\left(\lambda_{s i}\right)+\sigma_{e}\left(\lambda_{s i}\right)\right] \Gamma_{s i}}{h v_{s i} A}+\frac{1}{\tau}\right. \\
& \left.+\sum_{k} \frac{\left[P^{+}\left(z, \lambda_{k}\right)+P^{-}\left(z, \lambda_{k}\right)\right]\left[\sigma_{a}\left(\lambda_{k}\right)+\sigma_{e}\left(\lambda_{k}\right)\right] \Gamma_{k}}{h v_{k} A}\right\}^{-1} \text {, } \\
& \pm \frac{\mathrm{d} P_{k}^{ \pm}(z)}{\mathrm{d} z}=\Gamma_{k}\left\{\left[\sigma_{a}\left(\lambda_{k}\right)+\sigma_{e}\left(\lambda_{k}\right)\right] N_{2}(z)\right. \\
& \left.-\sigma_{a}\left(\lambda_{k}\right) N\right\} P_{k}^{ \pm}(z) \\
& -\alpha\left(\lambda_{p}\right) P_{k}^{ \pm}(z) \\
& +2 \Gamma_{k} \sigma_{e}\left(\lambda_{k}\right) N_{2}(z) \frac{h c^{2}}{\lambda_{k}^{3}} \Delta \lambda, \\
& \pm \frac{\mathrm{d} P_{s 1}^{ \pm}(z)}{\mathrm{d} z}=\Gamma_{s 1}\left\{\left[\sigma_{a}\left(\lambda_{s 1}\right)+\sigma_{e}\left(\lambda_{s 1}\right)\right] N_{2}(z)\right. \\
& \left.-\sigma_{a}\left(\lambda_{s 1}\right) N(z)\right\} P_{s 1}^{ \pm}(z) \\
& -\alpha\left(\lambda_{p}\right) P_{s 1}^{ \pm}(z)+2 \Gamma_{s 1} \sigma_{e}\left(\lambda_{s 1}\right) N_{2}(z) \frac{h c^{2}}{\lambda_{s 1}^{3}} \Delta \lambda \\
& -\frac{g_{R}}{A} \frac{\lambda_{s 2}}{\lambda_{s 1}} P_{s 1}^{ \pm}\left(P_{s 2}^{+}+P_{s 2}^{-}\right), \\
& \pm \frac{\mathrm{d} P_{s 2}^{ \pm}(z)}{\mathrm{d} z}=\Gamma_{s 2}\left\{\left[\sigma_{a}\left(\lambda_{s 2}\right)+\sigma_{e}\left(\lambda_{s 2}\right)\right] N_{2}(z)\right. \\
& \left.-\sigma_{a}\left(\lambda_{s 2}\right) N(z)\right\} P_{s 2}^{ \pm}(z) \\
& -\alpha\left(\lambda_{p}\right) P_{s 2}^{ \pm}(z)+2 \Gamma_{s 2} \sigma_{e}\left(\lambda_{s 2}\right) N_{2}(z) \frac{h c^{2}}{\lambda_{s 2}^{3}} \Delta \lambda \\
& +\frac{g_{R}}{A} P_{s 2}^{ \pm}\left(P_{s 1}^{+}+P_{s 1}^{-}\right) \\
& -\frac{g_{R 1}}{A} \frac{\lambda_{s 3}}{\lambda_{s 2}} P_{s 2}^{ \pm}\left(P_{s 3}^{+}+P_{s 3}^{-}\right)+2 h v_{2} \Delta v_{2}, \\
& \pm \frac{\mathrm{d} P_{s 3}^{ \pm}(z)}{\mathrm{d} z}=\Gamma_{s 3}\left\{\left[\sigma_{a}\left(\lambda_{s 3}\right)+\sigma_{e}\left(\lambda_{s 3}\right)\right] N_{2}(z)\right. \\
& \left.-\sigma_{a}\left(\lambda_{s 3}\right) N(z)\right\} P_{s 3}^{ \pm}(z)-\alpha\left(\lambda_{p}\right) P_{s 3}^{ \pm}(z) \\
& +2 \Gamma_{s 3} \sigma_{e}\left(\lambda_{s 3}\right) N_{2}(z) \frac{h c^{2}}{\lambda_{s 3}^{3}} \Delta \lambda \\
& +\frac{g_{R 1}}{A} P_{s 3}^{ \pm}\left(P_{s 2}^{+}+P_{s 2}^{-}\right)+2 h v_{3} \Delta v_{3} .
\end{aligned}
$$




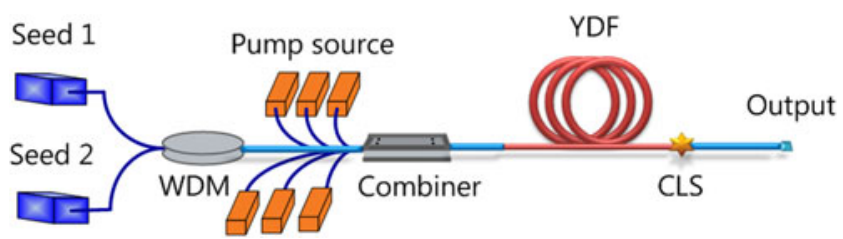

Figure 1. The basic system setup of the NFA.

The emission spectrum of Yb-doped fiber (from $970 \mathrm{~nm}$ to $1200 \mathrm{~nm}$ ) can be divided into discrete spectral channels with width of $\Delta \lambda$. The subscript $k$ represents the $k$ th channel but $p, s_{1}$ and $s_{2}$ represent the pump and two signal waves specially. The superscript \pm corresponds to positive and negative directions, respectively. $N(z)$ is the $\mathrm{Yb}$ ions concentration distribution along the fiber, for passive fiber $N(z)=$ $0 ; N_{2}(z)$ is the excited state population; $P_{s i}$ represents the signal power; $P\left(z, \lambda_{k}\right)$ is the power of laser $\lambda_{k} ; \sigma_{a}$ and $\sigma_{e}$ are $\mathrm{Yb}$ absorption and emission cross sections, respectively ${ }^{[41]}$. $\Gamma$ is the overlapping factor between the pump (ASE signal) and the fiber doped area. $g_{R}$ is the Raman gain coefficient; $\alpha$ is the loss coefficient. $2 h v \Delta v$ is the Raman noise and the factor 2 corresponds to two polarization states. $h$ is the Planck constant; $v$ is frequency; $\Delta v$ is bandwidth of the signal. For spontaneous Raman noise we assume the bandwidth equals the gain bandwidth that is about $40 \mathrm{THz}$.

The boundary conditions can be described by the following equations:

$$
\begin{aligned}
P^{+}\left(0, \lambda_{k, s i}\right) & =R_{1}\left(\lambda_{k, s i}\right) P^{-}\left(0, \lambda_{k, s i}\right)+P_{0}^{+}\left(\lambda_{k, s i}\right), \\
P^{-}\left(L, \lambda_{k, s i}\right) & =R_{2}\left(\lambda_{k, s i}\right) P^{+}\left(L, \lambda_{k, s i}\right)+P_{0}^{-}\left(\lambda_{k, s i}\right),
\end{aligned}
$$

where $R_{1}$ and $R_{2}$ refer to the reflectivity in the left and right side, respectively. Then this model can be numerically calculated by the finite-difference method ${ }^{[42]}$.

\section{Numerical analysis of nonlinear fiber amplifier}

\subsection{Power scaling potential of NFA}

SRS is a main restriction for the power scaling of wide bandwidth YDFA. There is still not a straightforward technique that can suppress SRS effectively without introducing any drawback in YDFA. In this section we would like to show the advantage of the NFA in the potential of suppressing SRS by using a numerical example. The parameters used in the calculation are shown in Table 1. It is a co-pumping scheme with power of $8000 \mathrm{~W}$. The gain fiber is $20 / 400 \mu \mathrm{m}$ (core/inner diameter) double cladding YDF.

Firstly, we calculate a traditional case of only the $1070 \mathrm{~nm}$ laser in the seed. The seed power is $200 \mathrm{~W}$. The power distribution along the fiber is shown in Figure 2. It can be found in this case that the signal power can reach more

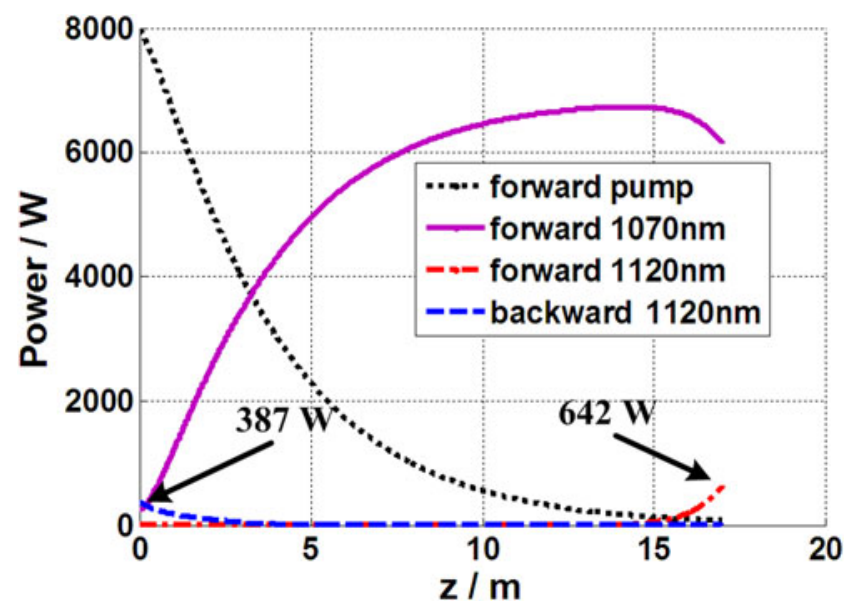

Figure 2. The power distribution of pump, signal, and Raman waves in forward and backward propagating directions. It can be found that Raman Stokes wave $(1120 \mathrm{~nm})$ has arisen in both directions, and the power is $642 \mathrm{~W}$ and $387 \mathrm{~W}$ for forward and backward directions, respectively.

Table 1. The parameters of the calculated fiber amplifier.

\begin{tabular}{llllll}
\hline Parameter & Value & Unit & Parameter & Value & Unit \\
\hline$\lambda_{p}$ & 976 & $\mathrm{~nm}$ & $\lambda_{s 1}$ & 1070 & $\mathrm{~nm}$ \\
$\lambda_{s 2}$ & 1120 & $\mathrm{~nm}$ & $\lambda_{s 3}$ & 1180 & $\mathrm{~nm}$ \\
$d_{\text {core }}$ & 20 & $\mu \mathrm{m}$ & $d_{\text {inner-clad }}$ & 400 & $\mu \mathrm{m}$ \\
$P_{p}$ & 8000 & $\mathrm{~W}$ & $\tau$ & 0.84 & $\mathrm{~ms}$ \\
$P_{0}^{+}(s 1)$ & 200 & $\mathrm{~W}$ & $\Gamma_{k}$ & 0.8 & - \\
$L$ & 17 & $\mathrm{~m}$ & $\alpha$ & $2 \times 10^{-3}$ & $\mathrm{~m}^{-1}$ \\
$\Delta v_{1}$ & 0.3 & $\mathrm{THz}$ & $\Delta v_{2}$ & 0.3 & $\mathrm{THz}$ \\
$\Delta v_{3}$ & 40 & $\mathrm{THz}$ & $N_{0}$ & $4.33 \times 10^{25}$ & $\mathrm{~m}^{-3}$ \\
$g_{R}$ & $0.5 \times 10^{-13}$ & $\mathrm{~m} / \mathrm{W}$ & $g_{R}$ & $0.48 \times 10^{-13}$ & $\mathrm{~m} / \mathrm{W}$ \\
\hline
\end{tabular}

than $6000 \mathrm{~W}$ if other nonlinear effects or thermal effects are ignored. However, such a system is unpractical for Raman Stokes wave $(1120 \mathrm{~nm})$ that can be found in both directions. Especially in the backward direction, the power of $1120 \mathrm{~nm}$ laser in the fiber core is about $387 \mathrm{~W}$, which is a big hidden danger for the high-power laser system. From this point of view, SRS is a limitation of the traditional Yb-doped fiber amplifier system. For comparison, we would like to give an example with similar condition for the NFA. The only change is that a $10 \mathrm{~W} 1120 \mathrm{~nm}$ laser is added in the seed. The $1120 \mathrm{~nm}$ laser corresponds to the first-order Stokes wave of $1070 \mathrm{~nm}$ laser. The other parameters of the amplifier are the same as that shown in Table 1.

Figure 3 is the calculated results of the NFA. In this amplifier, the $1070 \mathrm{~nm}$ laser is firstly amplified by the ytterbium gain, and as the $1120 \mathrm{~nm}$ laser propagates in the fiber core, it reaches the Raman threshold and begins to dominate the following amplification ${ }^{[34]}$. Finally, the power of $1070 \mathrm{~nm}$ laser is all transferred to the Stokes wave $(1120 \mathrm{~nm})$ at the output end. It can be found in Figure 3(b) that the sum of the laser power of $1070 \mathrm{~nm}$ and $1180 \mathrm{~nm}$ is less than $5 \mathrm{~W}$. At the backward output end, seen in Figure 3(c), the total output 

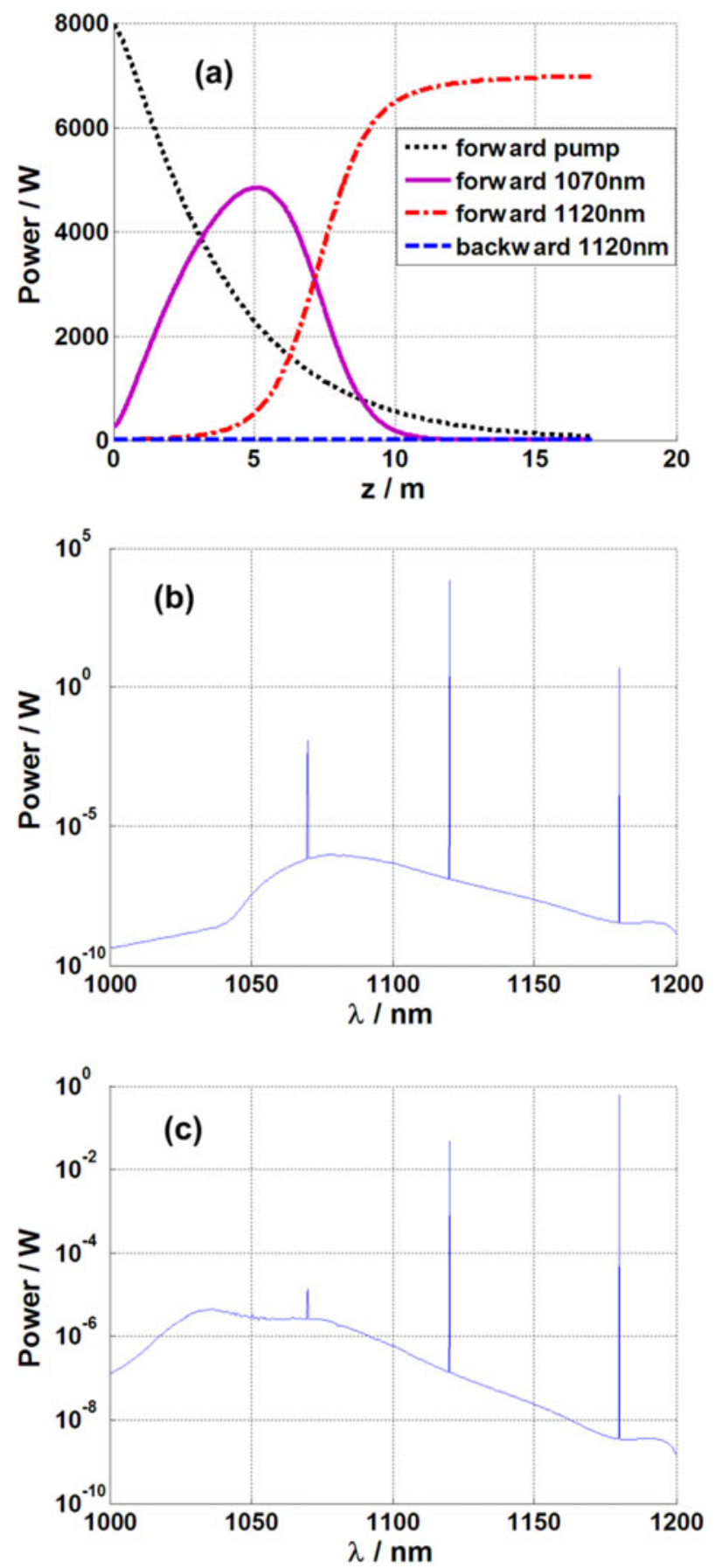

Figure 3. (a) The power distribution of the pump, signal, and first-order Stokes waves; (b) the forward and (c) backward output spectra of the NFA. The seed is consisted of $200 \mathrm{~W} 1070 \mathrm{~nm}$ laser and $10 \mathrm{~W} 1120 \mathrm{~nm}$ laser, respectively.

power in the fiber core is also small (less than $1 \mathrm{~W}$ ). So in this NFA, the SRS would not limit the power amplification, indicating such an amplifier has higher SRS threshold than the case of conventional YDFA. It should be noted that in the calculation the bandwidth of the laser is ignored, but it has little influence on the calculation of Raman effect

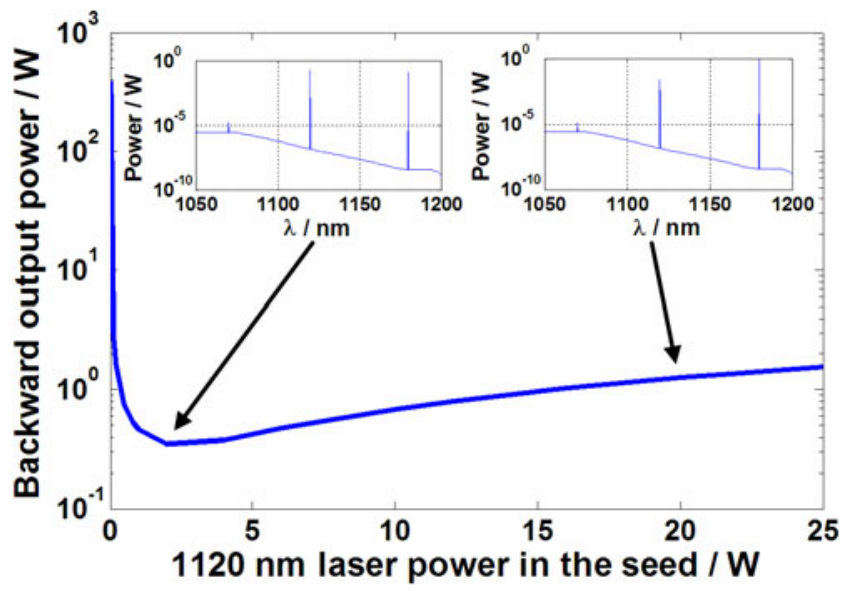

Figure 4. The dependence of backward output power on the power of $1120 \mathrm{~nm}$ seed laser. Insets are the output spectra in backward direction at different power.

because of the wide bandwidth of Raman gain spectrum ${ }^{[43]}$. Accordingly, the spectral broadening of the $1070 \mathrm{~nm}$ laser in real experiment would not obviously reduce the gain of Raman Stokes wave for the conventional case of seed with 1-3 nm bandwidth.

\subsection{Effect of suppressing backscattered Stokes light}

From the numerical example mentioned in Section 3.1, we can also find that the NFA has the ability to suppress the back propagating light. With the help of the nonlinear interaction of the forward propagating $1070 \mathrm{~nm}$ and $1120 \mathrm{~nm}$ laser, the backward spontaneous Raman Stokes wave has been sufficiently suppressed. To quantificationally analyze the function of the Stokes wave in the seed on the generation of backward output laser, we calculated the backward output power of the amplifier proposed in Section 3.1 under conditions of different injected $1120 \mathrm{~nm}$ seed power. The result is shown in Figure 4. It is shown that there is a 'perfect power' for $1120 \mathrm{~nm}$ seed laser to make the backward output power minimal. In this case that the 'perfect power' is about $2 \mathrm{~W}$, when the power of $1120 \mathrm{~nm}$ laser is smaller than this value, the seed is too weak to totally suppress the backward waves. However, high-power $1120 \mathrm{~nm}$ seed laser is not always good in decreasing the backward waves. As the $1120 \mathrm{~nm}$ laser power grows, the high-order Raman wave $(1180 \mathrm{~nm})$ starts to obtain gain due to the high-power seed induced Raman nonlinear interaction ${ }^{[44]}$. It can be understood by the inset of Figure 4. They are output spectra in backward direction. The high $1120 \mathrm{~nm}$ laser power case would result in more $1180 \mathrm{~nm}$ laser generation. 
Table 2. Parameters used to calculate the thermal distribution.

\begin{tabular}{llllll}
\hline Parameter & Value & Unit & Parameter & Value & Unit \\
\hline$k_{1}$ & 1.38 & $\mathrm{~W} /(\mathrm{m} \cdot \mathrm{K})$ & $a$ & 10 & $\mu \mathrm{m}$ \\
$k_{2}$ & 1.38 & $\mathrm{~W} /(\mathrm{m} \cdot \mathrm{K})$ & $b$ & 200 & $\mu \mathrm{m}$ \\
$k_{3}$ & 0.2 & $\mathrm{~W} /(\mathrm{m} \cdot \mathrm{K})$ & $c$ & 250 & $\mu \mathrm{m}$ \\
$h_{\text {heat }}$ & 1000 & $\mathrm{~W} /\left(\mathrm{m}^{2} \cdot \mathrm{K}\right)$ & $T_{c}$ & 293 & $\mathrm{~K}$ \\
\hline
\end{tabular}

\subsection{Heat analysis of NFA}

Fiber laser has the advantage on thermal conduction due to its special geometry. But for high-power fiber laser system, fibers are not completely immune from thermal effects, so reducing the thermal burden is one of the most important things to guaranty the system running safety. Theoretically, the quantum defect of the nonlinear fiber amplifier is larger than that of conventional fiber amplifier because of the using of longer signal wavelength (e.g., $1120 \mathrm{~nm}$ compared with $1070 \mathrm{~nm}$ ). In this section, we would compare the temperature distribution of these two kinds of amplifiers. The center temperature of the core $T_{0}$ in the YDF can be described by Equations (8) and (9) ${ }^{[45]}$.

$$
\begin{aligned}
T_{0}= & T_{c}+Q_{0} a^{2}\left[\frac{1}{2 h_{\text {heat }} c}+\frac{1}{4 k_{1}}+\frac{1}{2 k_{2}} \ln \left(\frac{b}{a}\right)\right. \\
& \left.+\frac{1}{2 k_{3}} \ln \left(\frac{c}{a}\right)\right], \\
Q_{0}(z)= & {\left[\left|\frac{\mathrm{d} P_{p}^{+}}{\mathrm{d} z}\right|+\left|\frac{\mathrm{d} P_{p}^{-}}{\mathrm{d} z}\right|\right.} \\
& \left.-\sum_{i}^{k, s_{1}, s_{2}, s_{3}}\left(\left|\frac{\mathrm{d} P_{i}^{+}}{\mathrm{d} z}\right|+\left|\frac{\mathrm{d} P_{i}^{-}}{\mathrm{d} z}\right|\right)\right] / \pi a^{2},
\end{aligned}
$$

where $k_{1}, k_{2}$, and $k_{3}$ are the thermal conductivities in core, inner cladding, and outer cladding, respectively, and $a, b$, $c$ are the diameter of the core, inner cladding, and outer cladding, respectively. $T_{c}$ is the coolant temperature. $h_{\text {heat }}$ is the convective heat transfer coefficient. $Q_{0}(z)$ is the heat power density of the core, which can be calculated by Equation (9).

We calculated the temperature distribution of the core center for the example proposed in Section 3.1, which is shown in Figure 5(a). The parameters used in the calculation are listed in Table 2. In the forward pumping scheme, the temperature distributed tendency of the NFA is similar with conventional fiber amplifier. The hottest point usually locates in the front part of the amplifier and the temperature gradually decreases along the fiber. But due to the further energy transfer from $1070 \mathrm{~nm}$ to $1120 \mathrm{~nm}$, there is an additional energy loss in the middle of the YDF for the NFA, resulting in the temperature rising. The second temperature peak, however, is far lower $\left(50^{\circ} \mathrm{C}\right.$ in this case) than the original temperature peak. It means the NFA would not bring additional stable thermal burden for a uniform cooling
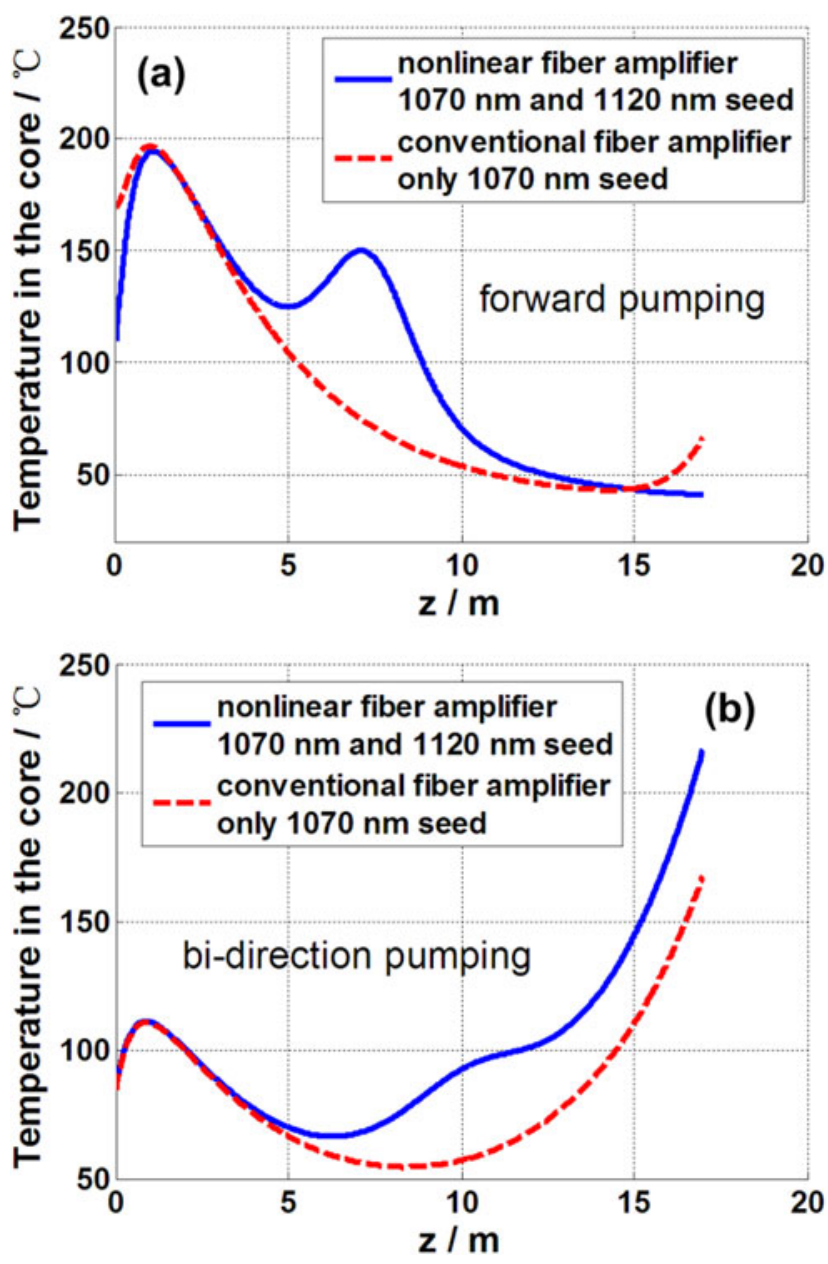

Figure 5. The center temperature of the core for NFA and conventional amplifier in (a) forward pumping scheme and (b) bi-direction pumping scheme. In the calculation, all the parameters of the bi-direction pumping scheme are the same as of the forward pumping scheme, excepting the pump power is divided equally into two directions.

high-power fiber laser system. So it still can work safely in conventional forward pumping fiber amplifier.

In the forward pumping NFA, the energy extraction can roundly divided into two parts. The first part is the amplification of the short signal wavelength laser $(1070 \mathrm{~nm})$, in which the ytterbium gain contributes more. And the second part is the nonlinear amplification, which requires the power of short signal wavelength laser to reach the nonlinear threshold. Consequently, the nonlinear effect induced energy transfer happens in the latter half of the fiber amplifier. But in the backward pumping or bi-direction pumping configurations, the nonlinearity related energy extraction and the $\mathrm{Yb}$ ions related amplification would be overlapped in the same piece of fiber, which will result in more thermal burden generation compared with conventional YDFA. Figure 5(b) is the center temperature in the core for a bi-direction pumping configuration with pump power of $4000 \mathrm{~W}$ in each side. At the output end, higher temperature can be found for the NFA. So in order to avoid additional thermal burden, 


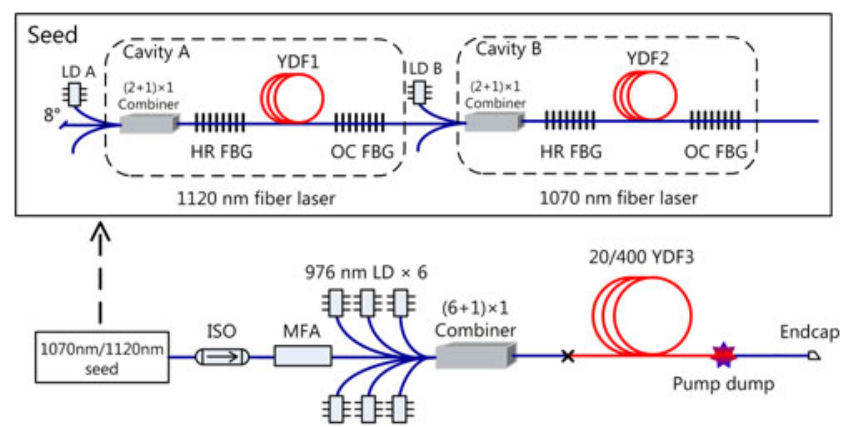

Figure 6. The experimental setup of the NFA ${ }^{[34]}$.

NFA is suggested to apply the forward pumping scheme in high-power laser amplifier.

\section{Experimental study on nonlinear fiber amplifier}

\subsection{Laser diode pumped high-power NFA}

In recent years, laser diode pumped high-power NFA has been demonstrated by several independent groups. In this sub-section, we will generally review the high-power experimental result achieved in our group.

As a proof-of-concept demonstration, we built an NFA system as shown in Figure $6^{[34]}$. The seed is composed of fiber lasers working at $1070 \mathrm{~nm}$ and $1120 \mathrm{~nm}$. The gain fiber in the amplifier stage is a 45 -meters-long $20 / 400 \mu \mathrm{m}$ YDF with a nominal cladding absorption coefficient of $1.3 \mathrm{~dB} / \mathrm{m}$. After the YDF, a pump dump is connected to stripe unabsorbed pump light and cladding mode. A homemade endcap is spliced in the end to avoid unwanted end reflection. The YDF is pumped by six $976 \mathrm{~nm}$ laser diodes with a total available power of $890 \mathrm{~W}$. In the experiment, the $1120 \mathrm{~nm}$ laser power is $8 \mathrm{~W}$ and the total seed power is about $30 \mathrm{~W}$. The measured total output power and $1120 \mathrm{~nm}$ power are shown in Figure 7. The $1120 \mathrm{~nm}$ power is achieved by integrated corresponding wavelength band in the output spectra. At the full pump power, the total output is $773 \mathrm{~W}$ and the maximum $1120 \mathrm{~nm}$ power is about $732 \mathrm{~W}$. We also plotted the theoretical result by numerically solving the models proposed in Section 2 and shown in Figure 7, and it could be seen that the experimental results agree well with theoretical ones.

After that we aim at more powerful NFA. The system shown in Figure 6 is redesigned ${ }^{[36]}$. The length of active fiber is shortened to be $26 \mathrm{~m}$ and the pump source is composed of two $976 \mathrm{~nm}$ LDs and four $915 \mathrm{~nm}$ LDs with maximum pump power of $2020 \mathrm{~W}$. The experimental results are shown in Figure 8. The total output power increases nearly linearly with the pump power and so does the $1120 \mathrm{~nm}$ laser. The maximum output power is $1655 \mathrm{~W}$ when the $2010 \mathrm{~W}$ pump power is launched into the amplifier and the power

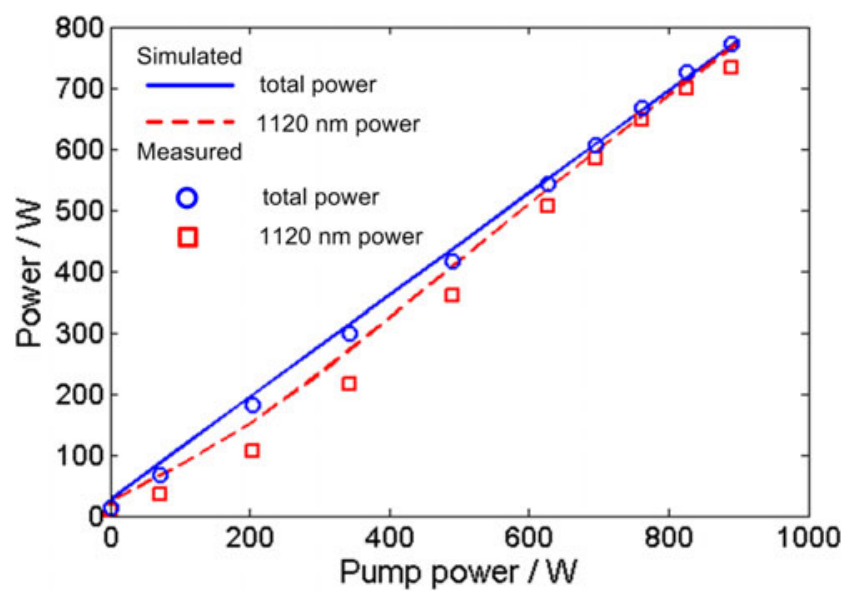

Figure 7. Theoretical prediction and experimental results of NFA.

of $1120 \mathrm{~nm}$ laser is about $1521 \mathrm{~W}$ with optical efficiency of $75.6 \%$, which is the highest power reported in 1100 $1200 \mathrm{~nm}$ range at that time. In the whole process of power scaling, the power of $1070 \mathrm{~nm}$ laser is less than $200 \mathrm{~W}$ and in the end only $96 \mathrm{~W} 1070 \mathrm{~nm}$ laser is residual in the output. The power ratio of $1120 \mathrm{~nm}$ laser turns from $30 \%$ to $96 \%$, when the dual-wavelength seed passes through the amplifier as a result of the Raman amplification. The $3 \mathrm{~dB}$ bandwidth of the $1120 \mathrm{~nm}$ laser broadens from $0.35 \mathrm{~nm}$ to $1.4 \mathrm{~nm}$ when the LDs turned on. At the total output power of about $1 \mathrm{~kW}$, a new wavelength peaking at $1175 \mathrm{~nm}$ starts to arise due to Raman-assisted-amplified FWM. The power proportion of this signal is only $0.7 \%$ at the full power. It is interesting that another two new wavelengths (1091 nm and $1149 \mathrm{~nm}$ ) appear when the total output power is about $1.5 \mathrm{~kW}$. The frequency differences of these two wavelengths to $1120 \mathrm{~nm}$ are equal, so we believe it is also caused by FWM. Though there are several new wavelengths in the output, the power ratio of $1120 \mathrm{~nm}$ laser still reaches $91.9 \%$.

It is to be noted that the concept of NFA can be extended to polarization-maintained fiber amplification straightforwardly, and we have achieved an output power of $1181 \mathrm{~W}$ with polarization-extinction ratio (PER) of $18.2 \mathrm{~dB}^{[38]}$.

\subsection{Tandem-pumped high-power NFA}

As indicated in previous discussions, NFA has the potential to break the power limitation induced by SRS during the power scaling process, and then the next power limitation might be the brightness of pump diode. In most of present high-power fiber laser systems, laser diodes are used as pump source. Recently, tandem pumping technique, which uses 'fiber laser' to pump active fiber, has been under intensive research, where the brightness of the pump laser is significantly increased ${ }^{[3,46-49]}$. In the present sub-section, we demonstrate the NFA in tandem pumping scheme for the first time. 

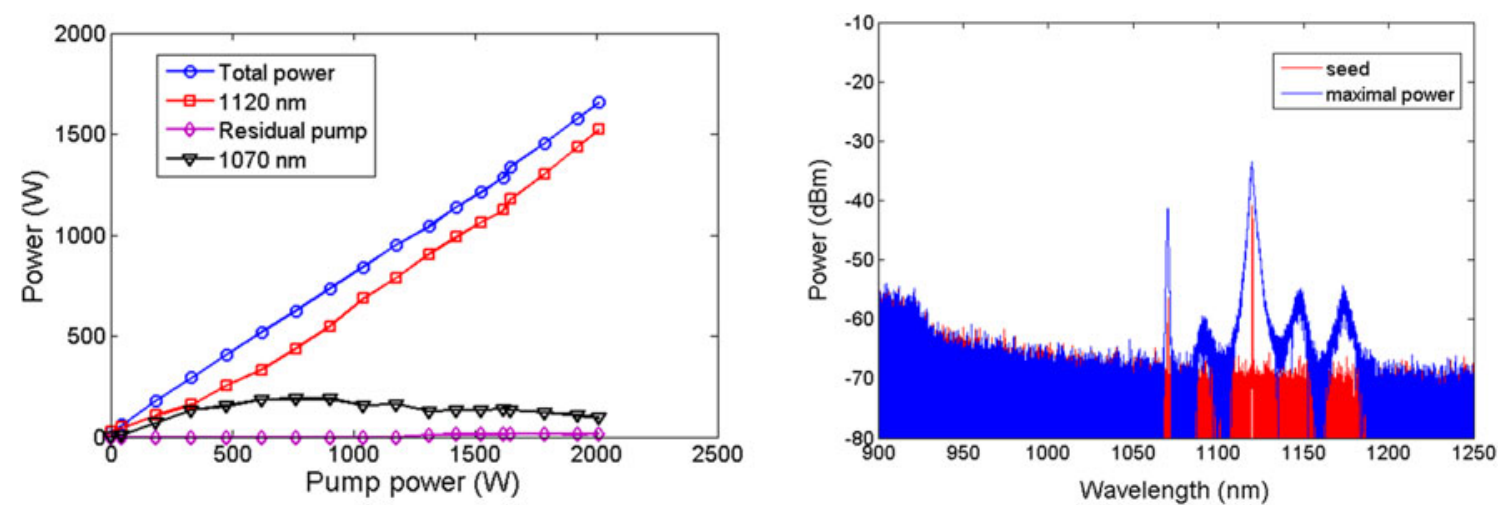

Figure 8. Experimental result of $1.5 \mathrm{~kW} \mathrm{NFA}{ }^{[36]}$.

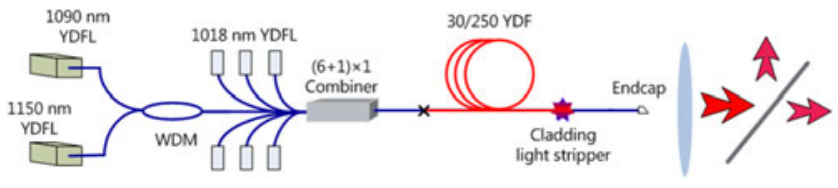

Figure 9. The experimental setup of the tandem-pumped NFA.

As shown in Figure 9, the system setup of tandem-pumped NFA is similar to Figure 6. The seed is composed of fiber lasers working at $1090 \mathrm{~nm}$ and $1150 \mathrm{~nm}$, and the output powers of those two lasers are $85 \mathrm{~W}$ and $7 \mathrm{~W}$, respectively. The measured output power of the two waves at different pump power is shown in Figure 10(a). The power of $1090 \mathrm{~nm}$ and $1150 \mathrm{~nm}$ laser evolves to $65 \mathrm{~W}$ and $16 \mathrm{~W}$ after passing through the amplifier. This power level is below the Raman amplification threshold, which is estimated to be about hundreds of watts. Thus only $\mathrm{Yb}$ gain serves for the amplification of $1150 \mathrm{~nm}$ laser. It indicates that the $1150 \mathrm{~nm}$ laser also has the ability to extract energy from $1090 \mathrm{~nm}$ laser through $\mathrm{Yb}$ ions. The pump source is powerful $1018 \mathrm{~nm}$ fiber laser fabricated in our group ${ }^{[50-52]}$, and the total available pump power is measured to be $1735 \mathrm{~W}$ in this experiment. The active fiber has $30 \mu \mathrm{m}$ core diameter and $250 \mu \mathrm{m}$ inner cladding diameter, and the cladding absorption coefficient at $1018 \mathrm{~nm}$ is measured to be about $0.6 \mathrm{~dB} / \mathrm{m}$ at a low power level, which is high enough thanks to the large pump overlap of the fiber. A piece of $38 \mathrm{~m}$ YDF is utilized to ensure adequate absorption. A pump stripper is spliced after the YDF to get rid of unwanted cladding light. Antireflection films are coated on the facet of the endcap to reduce backward reflection. The output lasers are collimated and separated by dichroic mirror for power and beam quality measurement.

When the pump power is injected, the total output power increases linearly with the change of the power ratio of the two waves. It should be noted that when the pump power is higher than $800 \mathrm{~W}, 1150 \mathrm{~nm}$ laser starts to increase fast while $1090 \mathrm{~nm}$ laser ceases rising. The $1150 \mathrm{~nm}$ laser gain mainly comes from the Raman amplification that becomes prominent as the power increases or waves propagate. Finally, the total output power is $1530 \mathrm{~W}$ with $1090 \mathrm{~nm}$ laser power of $703 \mathrm{~W}$ and $1150 \mathrm{~nm}$ laser power of $827 \mathrm{~W}$. The power of $1150 \mathrm{~nm}$ laser is the highest one at this wavelength as we know. The output spectrum at full power is shown in Figure 10(b).

For comparison, we also conduct the experiment where only $1090 \mathrm{~nm}$ laser is seeded. It is a conventional tandempumped Yb-doped fiber amplifier, in which the $56 \mathrm{~W}$ seed could be linearly boosted to $1530 \mathrm{~W}$, shown in Figure 11 . The total output power is nearly the same as the NFA case. The slope efficiency of the YDFA and NFA is $85.7 \%$ and $83.5 \%$, respectively. It can be found that the NFA works as efficiently as conventional YDFA. The difference mainly comes from the quantum defect of the energy conversion from $1090 \mathrm{~nm}$ laser to $1150 \mathrm{~nm}$ laser that is about $5 \%$.

It is to be noted that most of the published literatures for YDFL focus on the common wavelength band such as 1070$1080 \mathrm{~nm}$, whose operating power can achieve kilowatt level without too much difficulty. Because of the much smaller relative net gain and the significant amplified spontaneous emission at common band, lasing at 1120-1200 nm band (which also locates in the emission region of $\mathrm{Yb}$-doped silica fiber) is much more challenging ${ }^{[53-58]}$. Nevertheless, lasing at $1120-1200 \mathrm{~nm}$ band could find tremendous applications including biomedicine, new-style pump sources and remote sensing. Most of the demonstrated NFAs work at those wavelength bands, which provides a coincident solution for high-power laser source.

\section{Discussion}

In this section, we briefly discussed several new topics in high-power NFAs.

The first one is the FWM. In practical high-power NFA seeded by multi-wavelength laser, FWM might happen because the phase-mismatch could be compensated by the $\mathrm{Yb}$ gain $^{[59]}$. In this case, the modeling of high-power NFA might 

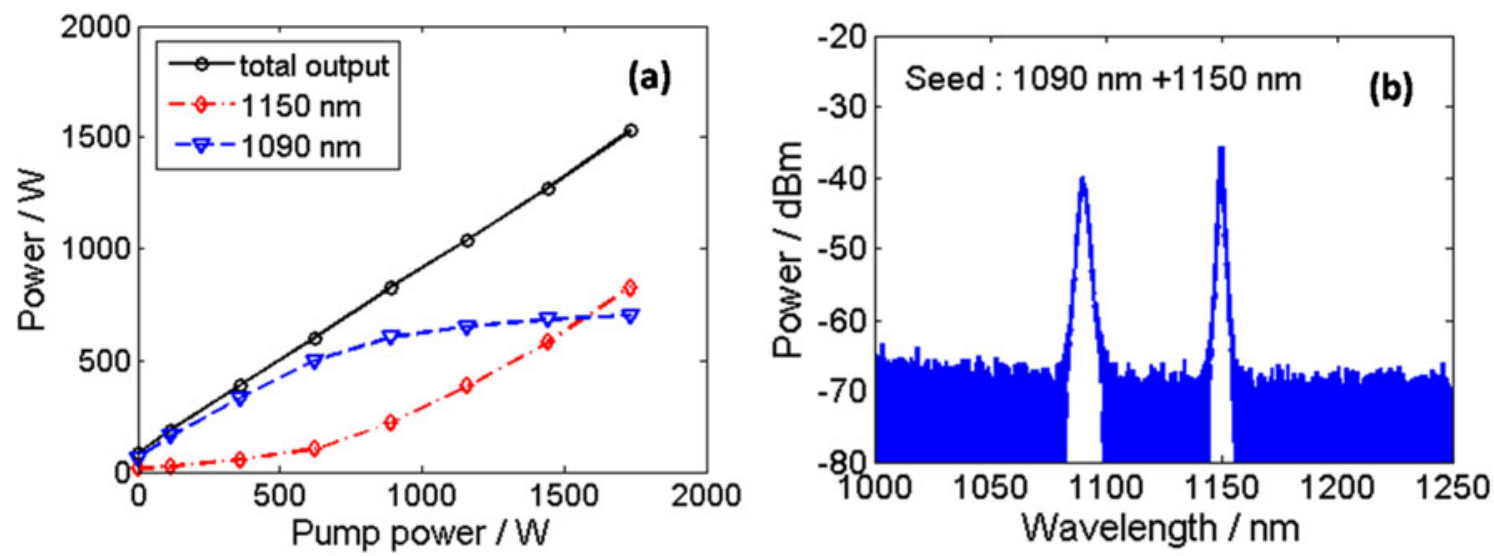

Figure 10. The output property of the tandem-pumped NFA: (a) output power; (b) spectrum at full power.

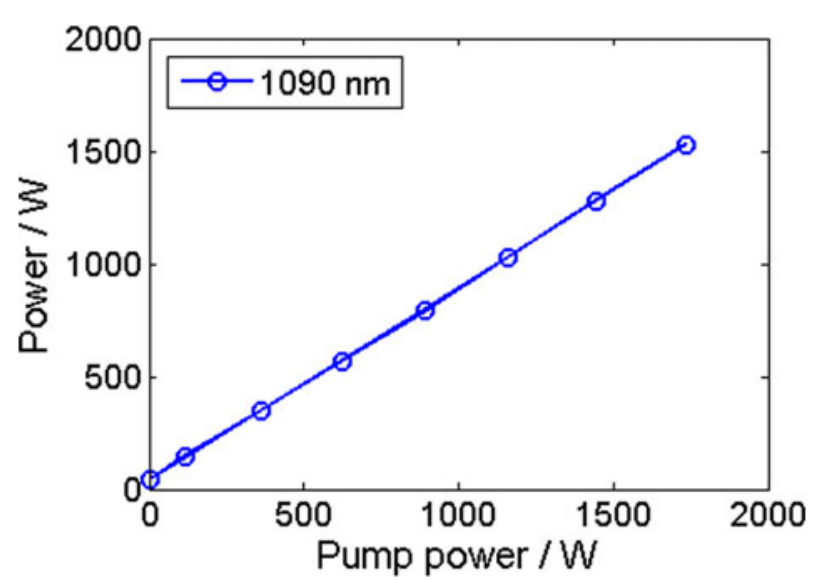

Figure 11. The measured $1090 \mathrm{~nm}$ laser power in the case of only $1090 \mathrm{~nm}$ seed with power of $56 \mathrm{~W}$.

be modified by taking FWM into consideration, which could be re-written as follows.

$$
\begin{aligned}
\pm \frac{\mathrm{d} E_{1}^{ \pm}}{\mathrm{d} z}= & j \gamma_{1}\left\{\left|E_{1}^{ \pm}\right|^{2}+(2-\rho)\left[\left|E_{2}^{+}\right|^{2}\right.\right. \\
& \left.\left.+\left|E_{2}^{-}\right|^{2}+\left|E_{3}^{+}\right|^{2}+\left|E_{3}^{-}\right|^{2}\right]\right\} E_{1}^{ \pm} \\
& -\frac{g_{R 1} \lambda_{2}}{2 \lambda_{1} A}\left(\left|E_{2}^{+}\right|^{2}+\left|E_{2}^{-}\right|^{2}\right) E_{1}^{ \pm} \\
& +\frac{g_{1}\left(N_{2}\right)}{2} E_{1}^{ \pm}+j \gamma_{1} E_{2}^{ \pm} E_{2}^{ \pm} E_{3}^{ \pm *} e^{ \pm j \Delta k z}, \\
\pm \frac{\mathrm{d} E_{2}^{ \pm}}{\mathrm{d} z}= & j \gamma_{2}\left\{\left|E_{2}^{ \pm}\right|^{2}+(2-\rho)\left[\left|E_{1}^{+}\right|^{2}\right.\right. \\
& \left.\left.+\left|E_{1}^{-}\right|^{2}+\left|E_{3}^{+}\right|^{2}+\left|E_{3}^{-}\right|^{2}\right]\right\} E_{2}^{ \pm} \\
& +\frac{g_{R 1}}{2 A}\left(\left|E_{1}^{+}\right|^{2}+\left|E_{1}^{-}\right|^{2}\right) E_{2}^{ \pm} \\
& -\frac{g_{R 2} \lambda_{3}}{2 \lambda_{2} A}\left(\left|E_{3}^{+}\right|^{2}+\left|E_{3}^{-}\right|^{2}\right) E_{2}^{ \pm} \\
& +\frac{g_{2}\left(N_{2}\right)}{2} E_{2}^{ \pm}+j \gamma_{2} E_{1}^{ \pm} E_{3}^{ \pm} E_{2}^{ \pm *} e^{\mp j \Delta k z},
\end{aligned}
$$

$$
\begin{aligned}
\begin{aligned}
& \pm \frac{\mathrm{d} E_{3}^{ \pm}}{\mathrm{d} z}= j \gamma_{3}\left\{\left|E_{3}^{ \pm}\right|^{2}+(2-\rho)\left[\left|E_{1}^{+}\right|^{2}\right.\right. \\
&\left.\left.+\left|E_{1}^{-}\right|^{2}+\left|E_{2}^{+}\right|^{2}+\left|E_{2}^{-}\right|^{2}\right]\right\} E_{3}^{ \pm} \\
&+\frac{g_{R 2}}{2 A}\left(\left|E_{2}^{+}\right|^{2}+\left|E_{2}^{-}\right|^{2}\right) E_{3}^{ \pm} \\
&+\frac{g_{3}\left(N_{2}\right)}{2} E_{3}^{ \pm}+j \gamma_{3} E_{2}^{ \pm} E_{2}^{ \pm} E_{1}^{ \pm *} e^{ \pm j \Delta k z}, \quad(12) \\
& \pm \frac{\mathrm{d} P_{p}^{ \pm}}{\mathrm{d} z}=g_{p} P_{p}^{ \pm}, \\
& N_{2}(z)=\frac{N_{0}}{A h c} \sum_{k} \Gamma_{k} \lambda_{k} \sigma_{a}\left(\lambda_{k}\right)\left(P_{k}^{+}+P_{k}^{-}\right) \\
& \frac{N_{0}}{\tau} \sum_{k} \Gamma_{k} \lambda_{k}\left(P_{k}^{+}+P_{k}^{-}\right)\left[\sigma_{a}\left(\lambda_{k}\right)+\sigma_{e}\left(\lambda_{k}\right)\right]
\end{aligned} \\
\left.g_{k}=p, 1,2,3\right),
\end{aligned}
$$

The superscript \pm corresponds to positive and negative directions, respectively. The subscript $k=p, 1,2,3$ represents the pump, signal, first-order and second-order Stokes waves, respectively. The complex electric-field envelope $E_{i}(z)=A_{i}(z) e^{j \varphi(z)}$ is related to power by $P_{i}(z)=A_{i}^{2}(z)$. The terms on the right-hand side of Equations (10)-(12) describe, respectively, self- and cross-phase modulation, SRS, amplification, and FWM. $\rho$ is the fractional Raman contribution (typically $\rho=0.18$ in silica), and $\gamma$ is the nonlinear coefficient. $\Delta k$ is the phase-mismatch. $g_{k}$ is the rare-earth-ion gain. The definitions of other symbols are the same as the model proposed in Section 2.

The boundary conditions can be described by the following equations.

$$
\begin{aligned}
& P^{+}\left(0, \lambda_{k}\right)=R_{1}\left(\lambda_{k}\right) P^{-}\left(0, \lambda_{k}\right)+P_{0}^{+}\left(\lambda_{k}\right), \\
& P^{-}\left(L, \lambda_{k}\right)=R_{2}\left(\lambda_{k}\right) P^{+}\left(L, \lambda_{k}\right)+P_{0}^{-}\left(\lambda_{k}\right) .
\end{aligned}
$$



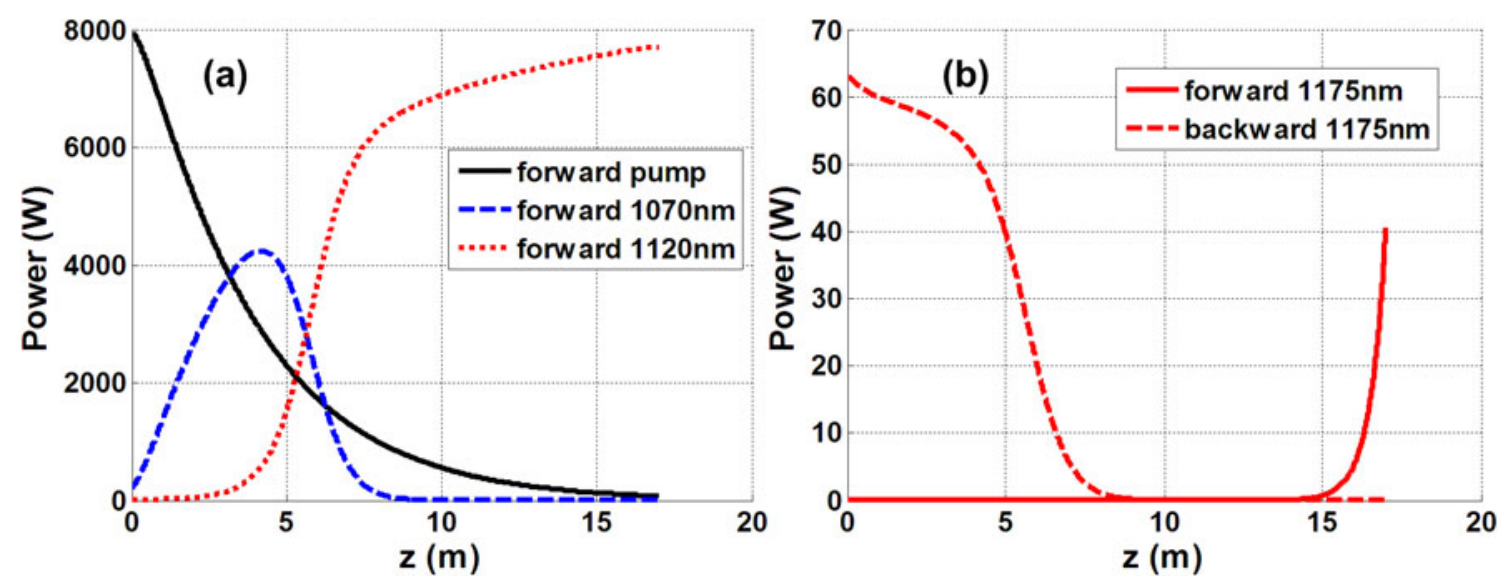

Figure 12. The power distribution of the NFA example proposed in Section 3.1 calculated by the FWM model.

$P_{0}^{ \pm}\left(\lambda_{k}\right)$ is the initially injected power of wavelength $\lambda_{k}$. Assuming $P_{0}^{ \pm}\left(\lambda_{k}\right)$ equals the thermal noise, i.e., $2 h v_{k} \Delta v_{k}$, if there is no power injected, here $\Delta v_{3}$ should be equal to $\Delta v_{1}$ because the interacted wavelengths have to satisfy the same frequency interval and similar bandwidth.

In order to evaluate the influence of FWM in the NFA, we calculate again the example proposed in Section 3.1 with the same parameters, except that the second-order Raman Stokes wavelength is $1175 \mathrm{~nm}$. In addition, we take $\gamma=$ $0.45 \times 10^{-3} \mathrm{~m}^{-1} \cdot \mathrm{W}^{-1}, \Delta k=200 \mathrm{~m}^{-1}$, and $\Delta v_{3}=\Delta v_{1}=$ $0.3 \mathrm{THz}$ in the calculation.

Figure 12 is the calculated power distribution. The power evolution of the involved waves is nearly the same as the results shown in Figure 3(a). The power of the second-order Stokes wave, however, is an order of magnitude higher than previous calculation. We also find that if the $1120 \mathrm{~nm}$ seed power reduced to $0.5 \mathrm{~W}$, the output power of $1175 \mathrm{~nm}$ could decrease to $6 \mathrm{~W}$ in both directions. It means the rare-earthion gain induced FWM would intensively affect the energy transfer in the NFA under some conditions. So the problems, such as how to reduce the influence of FWM, whether FWM effect is still obvious if the second-order Stokes wave is beyond the gain spectrum of the rare-earth ion, should be carefully studied.

The second one is MI. We have to note that MI has become a serious challenge for further scaling the output power ${ }^{[60-67]}$. Generally, MI could be attributed to the power coupling between fundamental mode and high-order mode supported by the fiber waveguide. Theoretical and experimental results have proved that the MI threshold would be higher if the core diameter of the active fiber is smaller ${ }^{[60,65]}$. In this case, tandem-pumped NFA, where larger-mode-area fiber is preferred to ensure sufficient absorption, would encounter complex nonlinear effect, i.e., the MI effect trends to transfer power to high-order mode, while the Raman gain provided by the NFA simultaneously has a self-cleaning effect that is apt to lower mode operation. MI in pure cladding pumped Raman fiber laser has been investigated ${ }^{[66]}$, and thus the coupling between $\mathrm{MI}$ and $\mathrm{Yb} / \mathrm{Raman}$ might have plenty nonlinear dynamics that should be further investigated.

The third one is PD effect. Since SRS effect suppression is no longer required, highly doped fiber, which is often used to shorten the fiber length, is also not required in high-power NFA. Moderately or lowly doped active fiber could be employed and thus PD effect suppression could be expected in NFA. However, as shown in Section 3.3, there is intrinsic difference in heat distribution inside the NFA, and the effect of the new heat generation mechanism on PD is an interesting topic. PD in NFA might also affect the MI threshold that has been observed in $\mathrm{YDFA}^{[68]}$.

Last but not the least, NFA in different wavelength bands, for example, $2 \mu \mathrm{m}$ band, has also been achieved ${ }^{[40]}$. We have to note that up to now there are no theoretical predictions. It is known that lasing at $>2.1 \mu \mathrm{m}$ is more difficult for Tm-doped fiber than for Ho-doped fiber ${ }^{[69]}$, however, Tmdoped fiber is relatively more mature than its Ho-doped counterpart ${ }^{[70-72]}$. In this case, it is worthwhile to study the feasibility of obtaining high-power laser at $>2.1 \mu \mathrm{m}$ band based on Tm/Raman NFA. The potential in power scaling of mid-infrared fiber laser ${ }^{[73]}$ based on rare-earth ion and Raman gain is another interesting topic.

\section{Conclusion}

Through theoretical investigation and experimental validation, it can be seen that NFA fully explores the power scaling potential of both rare-earth ions and SRS in cladding pumped fibers, while simultaneously settled the power limitation and hazard induced by SRS in classical high-power fiber laser system, and it opens a new physically straightforward and technically feasible solution for obtaining ultra-high-power fiber lasers. Tremendous study might be illuminated by this concept to develop high-power fiber laser system. In 
addition, the plenty new physical insight within the amplifier that includes several nonlinear optical effects coupled with each other also might be interesting for theoretical studies.

\section{Acknowledgements}

This work was supported by the Natural Science Foundation of Hunan Province, China (No. 2018JJ2474) and the Huo Yingdong Education Foundation of China.

\section{References}

1. M. N. Zervas and C A. Codemard, IEEE J. Sel. Top. Quantum Electron. 20, 219 (2014).

2. J. W. Dawson, M. J. Messerly, R. J. Beach, M. Y. Shverdin, E. A. Stappaerts, A. K. Sridharan, P. H. Pax, J. E. Heebner, C. W. Siders, and C. P. J. Barty, Opt. Express 16, 13240 (2008).

3. J. Zhu, P. Zhou, Y. Ma, X. Xu, and Z. Liu, Opt. Express 19, 18645 (2011).

4. A. Rosales-Garcia, H. Tobioka, K. Abedin, H. Dong, Z. Várallyay, Á. Szabó, T. Taunay, S. Sullivan, and C. Headley, Proc. SPIE 9344, 93441G (2015).

5. Y. Wang, C. Xu, and H. Po, Opt. Commun. 242, 487 (2004).

6. Y. Wang, Opt. Eng. 44, 114202 (2005).

7. J. Kim, P. Dupriez, C. Codemard, J. Nilsson, and J. K. Sahu, Opt. Express 15, 5103 (2006).

8. Y. Mashiko, H. K. Nguyen, M. Kashiwagi, T. Kitabayashi, K. Shima, and D. Tanaka, Proc. SPIE 9728, 972805 (2015).

9. H. Yu, H. Zhang, H. Lv, X. Wang, J. Leng, H. Xiao, S. Guo, P. Zhou, X. Xu, and J. Chen, Appl. Opt. 54, 4556 (2015).

10. E. M. Dianov, M. E. Likhachev, and S. Fevrier, IEEE J. Sel. Top. Quantum Electron. 44, 20 (2009).

11. Y. Feng, L. Taylor, and D. Bonaccini Calia, Opt. Express 16, 10927 (2008).

12. S. A. Skubchenko, M. Y. Vyatkin, and D. V. Gapontsev, IEEE Photonics Technol. Lett. 16, 1014 (2004).

13. Y. Feng, L. R. Taylor, and D. B. Calia, Opt. Express 17, 23678 (2009).

14. H. Zhang, H. Xiao, P. Zhou, X. Wang, and X. Xu, IEEE Photon. J. 5, 1501706 (2013).

15. H. Zhang, P. Zhou, H. Xiao, and X. Xu, Laser Phys. Lett. 11, 75104 (2014).

16. V. R. Supradeepa and J. W. Nicholson, Opt. Lett. 38, 2538 (2013).

17. V. R. Supradeepa, J. W. Nichsolson, C. E. Headley, M. F. Yan, B. Palsdottir, and D. Jakobsen, Opt. Express 21, 7148 (2013).

18. H. Zhang, P. Zhou, X. Wang, X. Du, H. Xiao, and X. Xu, Opt. Express 23, 17138 (2015).

19. B. A. Cumberland, S. V. Popov, J. R. Taylor, O. I. Medvedkov, S. A. Vasiliev, and E. M. Dianov, Opt. Lett. 32, 1848 (2007).

20. X. Jin, Z. Lou, H. Zhang, J. Xu, P. Zhou, and Z. Liu, Opt. Lett. 41, 4923 (2016)

21. F. Vincent, B. Martin, C. Julien, and R. Vallée, Opt. Lett. 36, 4152 (2011).

22. M. Bernier, V. Fortin, N. Caron, M. El-Amraoui, Y. Messaddeq, and R. Vallée, Opt. Lett. 38, 127 (2013).

23. M. Bernier, V. Fortin, M. El-Amraoui, Y. Messaddeq, and R. Vallée, Opt. Lett. 39, 2052 (2014).

24. C. A. Codemard, P. Dupriez, Y. Jeong, J. K. Sahu, M. Ibsen, and J. Nilsson, Opt. Lett. 31, 2290 (2006).

25. J. Ji, C. A. Codemard, M. Ibsen, J. K. Sahu, and J. Nilsson, IEEE J. Sel. Top. Quantum Electron. 15, 129 (2009).
26. C. A. Codemard, J. Ji, J. K. Sahu, and J. Nilsson, Proc. SPIE 7580, $75801 \mathrm{~N}(2010)$.

27. S. I. Kablukov, E. I. Dontsova, E. A. Zlobina, I. N. Nemov, A. A. Vlasov, and S. A. Babin, Laser Phys. Lett. 10, 085103 (2013).

28. E. A. Zlobina, S. I. Kablukov, M. I. Skvortsov, I. N. Nemov, and S. A. Babin, Laser Phys. Lett. 13, 035102 (2016).

29. Y. Glick, V. Fromzel, J. Zhang, A. Dahan, N. Ter-Gabrielyan, R. Pattnaik, and M. Dubinskii, Laser Phys. Lett. 13, 065101 (2016).

30. Y. Glick, V. Fromzel, J. Zhang, N. Ter-Gabrielyan, and M. Dubinsii, Appl. Opt. 56, B97 (2017).

31. N. B. Terry, K. T. Engel, T. G. Alley, and T. H. Russell, Opt. Express 15, 602 (2007).

32. S. H. Baek and W. B. Roh, Opt. Lett. 29, 153 (2004).

33. L. Zhang, H. Jiang, S. Cui, and Y. Feng, Opt. Lett. 39, 1933 (2014).

34. H. Zhang, H. Xiao, P. Zhou, X. Wang, and X. Xu, Opt. Express 22, 10249 (2014).

35. L. Zhang, C. Liu, H. Jiang, Y. Qi, B. He, J. Zhou, X. Gu, and Y. Feng, Opt. Express 22, 18483 (2014).

36. H. Zhang, R. Tao, P. Zhou, X. Wang, and X. Xu, IEEE Photonics Technol. Lett. 27, 628 (2015).

37. Q. Xiao, P. Yan, D. Li, J. Sun, X. Wang, Y. Huang, and M. Gong, Opt. Express 24, 6758 (2016).

38. P. Ma, H. Zhang, L. Huang, X. Wang, P. Zhou, and Z. Liu, Opt. Express 23, 26499 (2015).

39. E. E. Rowen, G. Vashdi, J. Lasri, and E. Inbar, Proc. SPIE 8601, 86011J (2013).

40. J. Liu, F. Tan, H. Shi, and P. Wang, Opt. Express 22, 28383 (2014).

41. R. Paschotta, J. Nilsson, A. C. Tropper, and D. C. Hanna, IEEE J. Quantum Electron. 33, 1049 (1997).

42. Y. Wang and H. Po, J. Lightwave Technol. 20, 2262 (2003).

43. G. P. Agrawal, Nonlinear Fiber Optics, 4th ed. (Academic, San Diego, 2007).

44. J. Wang, D. Yan, S. Xiong, B. Huang, and C. Li, Opt. Express 24, 14463 (2016).

45. Y. Fan, B. He, J. Zhou, J. Zheng, H. Liu, Y. Wei, J. Dong, and Q. Lou, Opt. Express 19, 15162 (2011).

46. E. Stiles, Proceedings of the 5th International Workshop on Fiber Lasers (2009).

47. C. Wirth, O. Schmidt, A. Kliner, T. Schreiber, R. Eberhardt, and A. A. Tünnermann, Opt. Lett. 36, 3061 (2011).

48. D. Creeden, B. R. Johnson, G. A. Rines, and S. D. Setzler, Proc. SPIE 9081, 90810I (2014).

49. H. Xiao, J. Leng, H. Zhang, L. Huang, J. Xu, and P. Zhou, Appl. Opt. 54, 8166 (2015).

50. H. Xiao, P. Zhou, X. Wang, S. Guo, and X. Xu, IEEE Photonics Technol. Lett. 24, 1088 (2012).

51. H. Xiao, P Zhou, X. Wang, X. Xu, and Z. Liu, Laser Phys. Lett. 10, 065102 (2013).

52. H. Xiao, P. Zhou, X. L. Wang, S. F. Guo, and X. J. Xu, Laser Phys. Lett. 9, 748 (2012).

53. A. S. Kurkov, V. M. Paramonov, and O. I. Medvedkov, Laser Phys. Lett. 3, 503 (2006).

54. M. P. Kalita, S. Alam, C. Codemard, S. Yoo, A. J. Boyland, M. Ibsen, and J. K. Sahu, Opt. Express 18, 5920 (2010).

55. P. Zhou, X. Wang, H. Xiao, Y. Ma, and J. Chen, Laser Phys. 22, 823 (2012).

56. V. V. Dvoyrin, O. I. Medvedkov, and I. T. Sorokina, IEEE J. Quantum Electron. 49, 419 (2013).

57. H. Zhang, H. Xiao, P. Zhou, X. Wang, and X. Xu, Laser Phys. Lett. 10, 95106 (2013).

58. L. Huang, H. Zhang, X. Wang, and P. Zhou, IEEE Photonics J. 8, 1501407 (2016).

59. J. Fève, Opt. Express 15, 577 (2007). 
60. A. M. M. Johansen, K. R. Hansen, T. T. Alkeskjold, and J. Lægsgaard, Proc. SPIE 8961, 89612P (2014).

61. T. Eidam, C. Wirth, C. Jauregui, F. Stutzki, F. Jansen, H. Otto, O. Schmidt, T. Schreiber, J. Limpert, and A. Tünnermann, Opt. Express 19, 13218 (2011).

62. A. V. Smith and J. J. Smith, Opt. Express 19, 10180 (2011).

63. F. Jansen, F. Stutzki, H. Otto, T. Eidam, A. Liem, C. Jauregui, J. Limpert, and A. Tünnermann, Opt. Express 20, 3997 (2012).

64. I.-N. Hu, C. Zhu, C. Zhang, A. Thomas, and A. Galvanauskas, Proc. SPIE 8601, 860109 (2013).

65. R. Tao, P. Ma, X. Wang, P. Zhou, and Z. Liu, IEEE J. Quantum Electron. 51, 1600106 (2015).

66. S. Naderi, I. Dajani, J. Grosek, and T. Madden, Proc. SPIE 9344, 93442X (2015).
67. R. Tao, P. Ma, X. Wang, P. Zhou, and Z. Liu, Photon. Res. 3, 86 (2015).

68. M. Laurila, M. M. Jørgensen, K. R. Hansen, T. T. Alkeskjold, J. Broeng, and J. Lægsgaard, Opt. Express 20, 5742 (2012).

69. X. Jin, X. Du, X. Wang, P. Zhou, H. Zhang, X. Wan, and Z. Liu, Sci. Rep. 6, 30052 (2016).

70. Q. Wang, J. Geng, and S. Jiang, Opt. Eng. 53, 061609 (2014).

71. P. F. Moulton, G. A. Rines, E. V. Slobodtchikov, K. F. Wall, G. Frith, B. Samson, and A. L. Carter, IEEE J. Sel. Top. Quantum Electron. 15, 85 (2009).

72. X. Wang, P. Zhou, X. Wang, H. Xiao, and L. Si, Opt. Express 21, 32386 (2013).

73. S D. Jackson, Nat. Photon. 6, 429 (2012). 